\title{
Diffusion-Weighted Magnetic Resonance Imaging in Maxillary Sinuses Inflammatory Diseases: Report of Three Cases and Literature Review
}

\author{
Luciana Munhoz ${ }^{1}$, Reinaldo Abdala Júnior ${ }^{1}$, Rogério Abdala², Junichi Asaumi ${ }^{3}$, Emiko Saito Arita $^{1}$ \\ 'Department of Stomatology, School of Dentistry, São Paulo University, São Paulo, Brazil. \\ ${ }^{2}$ Centro de Diagnósticos Brasil, São Paulo, Brazil. \\ ${ }^{3}$ Departament of Oral and Maxillofacial Radiology, Okayama University, Okayama, Japan.
}

\author{
Corresponding Author: \\ Luciana Munhoz \\ Department of Stomatology, School of Dentistry \\ University of São Paulo \\ 2227 Lineu Prestes Avenue, 05508-000 São Paulo, SP \\ Brazil \\ Phone: +55 11 3091-7831 \\ Fax: +55 11 3091-7831 \\ E-mail: dra.lucimunhoz@usp.br
}

\begin{abstract}
Background: Magnetic resonance imaging is considered a preferable imaging examination in the diagnosis of inflammatory maxillary sinus disease and can provide precise sinonasal characterization. Diffusion-weighted magnetic resonance imaging and apparent diffusion coefficient are complementary magnetic resonance imaging tools that can be applied to the differentiation of sinus diseases. In this report, 3 cases of inflammatory maxillary sinus diseases imaging findings considering diffusion-weighted magnetic resonance imaging features were described. Additionally, a literature review considering the use of diffusion-weighted magnetic resonance imaging in inflammatory lesions is provided.

Methods: The cases reported were: presence of air-fluid levels, mucosal thickening and a mucous retention cyst. Conventional magnetic resonance imaging and apparent diffusion coefficient (ADC) maps, with ADC values were demonstrated. In the literature review, the studies considering inflammatory lesions were detailed, as well as ADC values established by investigators. Results: ADC values for presence of air-fluid levels, mucosal thickening and mucous retention cyst were respectively: $1.99 \mathrm{x}$ $10^{-3} \mathrm{~mm}^{2} / \mathrm{s} ; 1.83 \times 10^{-3} \mathrm{~mm}^{2} / \mathrm{s} ; 2.05 \times 10^{-3} \mathrm{~mm}^{2} / \mathrm{s}$.

Conclusions: It was observed that apparent diffusion coefficient values from the inflammatory lesions described in this report were different and apparent diffusion coefficient may be useful in the differentiation of these maxillary sinus alterations. Further larger sample investigations considering apparent diffusion coefficient values focusing in inflammatory lesions are recommended. The lack of studies considering the use of diffusion-weighted magnetic resonance imaging on inflammatory diseases diagnostic was the major limitation to the literature review.
\end{abstract}

Keywords: magnetic resonance imaging; paranasal sinuses; inflammatory disease; maxillary sinus.

Accepted for publication: 25 June 2018

To cite this article:

Munhoz L, Abdala Júnior R, Abdala R, Asaumi J, Arita ES.

Diffusion-Weighted Magnetic Resonance Imaging in Maxillary Sinuses Inflammatory Diseases: Report of Three Cases and Literature Review

J Oral Maxillofac Res 2018;9(2):e4

URL: http://www.ejomr.org/JOMR/archives/2018/2/e4/v9n2e4.pdf

doi: $10.5037 /$ jomr.2018.9204 


\section{INTRODUCTION}

The maxillary sinuses are the largest of all paranasal sinuses. They are known as pyramidal shape bone cavities with multiple functions: secreting mucus to humidify the nasal cavity and moistening the inspired air, also insulating air thermally; contributing to facial growth; absorbing impacts to the skull structures and decreasing the weight of the skull [1].

Maxillary sinus volume increases rapidly up to 12 years of age and stabilizes after last superior molar eruption [2]. Notwithstanding, superior molar loss induces maxillary sinus expansion, regardless of the age, resulting in alveolar bone height and width decrease. Bone remodeling after tooth extraction leads to considerable horizontal and vertical bone volume loss []ㅡ, which may compromise subsequent implant placement, as well as the position and appearance of the soft tissues in aesthetic areas [4]. Therefore, maxillary sinus augmentation is often applied to atrophic residual ridge to enable adequate implant placement in oral rehabilitation.

Although sinus floor elevation techniques are welldocumented and successful procedures $[\underline{5}, \underline{6}]$, the presence of sinonasal pathology is a contraindication for sinus augmentation surgery [7]. Failure may be associated with pre-existing or susceptibility to sinus diseases $[\underline{8}, \underline{9}]$ as well as a decrease in survival rates of implants due to postoperative maxillary sinusitis [10]. The careful imaging study of maxillary sinuses before surgical procedures is advocated to improve postoperative sinus surgery outcomes $[\underline{9}, \underline{11}, \underline{12}]$ and implant placement longevity in adjacent sinus areas. Moreover, dental professionals should be aware of the importance of the diagnosis of sinonasal inflammatory disease, and proper referring the patients to otorhinolaryngologic evaluation, not only before sinus augmentation procedures, but due to the fact that sinus inflammatory disease may be associated with toothache (mainly the acute forms of sinusitis) [13].

The gold standard of imaging examination to the maxillary sinus evaluation is the noncontrast, multiplanar, high resolution, thin-section multislice cone beam computed tomography (MCT) [14]. The main advantages of MCT are the great delineation of sinonasal anatomy, as well as patterns of bone changes, the presence of intrasinus calcifications and extend of sinonasal disease [14]. In dentistry, the introduction of cone-beam computed tomography (CBCT) has provided a relatively low-cost and lowradiation dose examination in comparison to MCT [15]. CBCT high spatial resolution in indispensable for evaluating potential implant sites [15] and also can be useful in maxillary sinus evaluation, considering the close relationship between upper posterior maxillary teeth and maxillary sinus floor. However, CBCT has inferior soft tissue contrast resolution, when compared to MCT [16]. Although soft tissue related alterations in the maxillary sinuses can also be evaluated by MCT and CBCT, magnetic resonance imaging (MRI) is the imaging examination which can provide a fine soft-tissue contrast resolution, and also allow precise sinus anatomical characterization, as well as differentiation between inflammatory sinus alterations [17].

Recently, MRI is often referred to as the preferable imaging examination in the diagnosis of inflammatory sinus disease $[\underline{18,19}]$ essentially when further maxillary sinus disease evaluation is needed. Diffusion-weighted MRI (DWI) is a conventional MRI complementary tool that can be employed to the depiction of sinus diseases [20-22] and analyses qualitatively water molecular random movements in intracellular medium. DWI can be translated into numerical values, named as "apparent diffusion

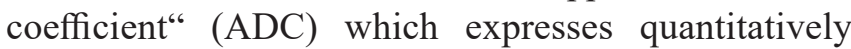
water movement.

Hence, the objective of this report is to describe and discuss MRI, DWI and ADC findings in 3 cases of inflammatory maxillary sinus alterations related to inflammatory diseases: presence of air-fluid level, mucosal thickening and mucous retention cyst and, additionally, to review the literature regarding the use of DWI in inflammatory sinus diseases as diagnostic tool.

\section{CASE DESCRIPTION AND RESULTS Imaging parameters and acquisition}

Non-contrast enhanced MRI and DWI images of the cases were collected using a $1.5 \mathrm{~T}$ superconducting magnet (Brivo MR355 Inspire; GE Healthcare, Chicago, Illinois, USA) with a standard head coil. The MRI and DWI parameters were the following: T1weighted spin-echo sequences (repetition time/echo time, TR/TE: 800/15 ms), T2-weighted fast sequences (TR/TE: 4,500/80 ms), DWI (TR/TE: 4,285/108 ms), $256 \times 256$ matrix , $20 \times 25 \mathrm{~cm}$ field of view, $5 \mathrm{~mm}$ section thickness, and $1-2 \mathrm{~mm}$ intersection gap. Diffusion-probing gradients were applied in all three orthogonal directions using the same strength. ADC maps were generated from all the axial DWI. ADC value of all cases reported was determined in ADC map considering a $5 \mathrm{~cm}$ region of interest (ROI) as central as possible and in the most significant part of the alteration. ROI was manually positioned 
in full concordance with 3 observers with experience in sinonasal evaluation by MRI. Mean ADC values generated by the ROIs in each ADC map positioning was addressed to the respective case report. A schematic explanation of ADC values determination is available on Figure 1.

\section{Literature review search}

For the literature review, the databases were searched and manuscripts up to January, 2018 were included, using the keywords "diffusion" combined with "sinonasal", "paranasal sinus", "maxillary sinus", "frontal sinus", ethmoid sinus "and "sphenoid sinus.

Only original English language studies were selected, as well as investigations considering exclusively paranasal sinus diseases. Then, from the selected articles, the information was extracted considering inflammatory sinonasal diseases, which were demonstrated in Table 1 and mentioned in the Discussion section.

\section{Case 1. Presence of air-fluid level}

A 71-year-old female patient was referred to MRI examination by her neurologist as a routine examination due to a cerebral microangiopathic gliosis previously detected. Sinonasal continuous secretion was a secondary complaint, reported previously to the MRI examination. Considering the maxillary sinus findings, in the case exhibited, MRI shows the maxillary sinus partially filled by a homogeneous content, isointense to hyperintense

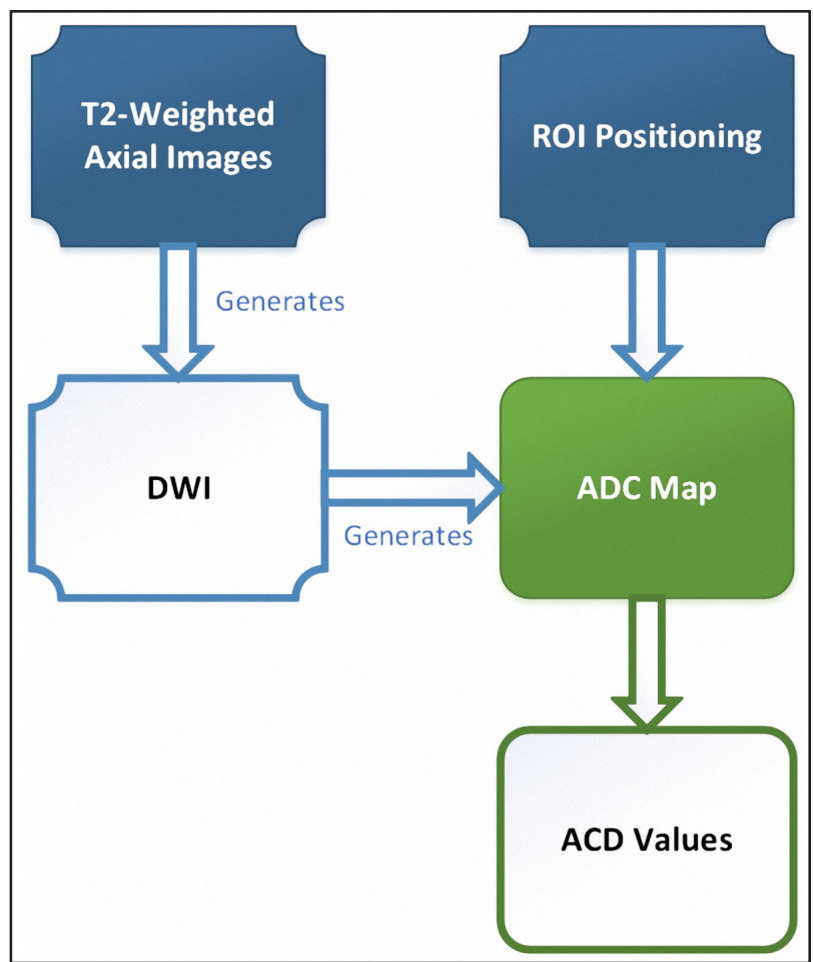

Figure 1. Schematic explanation of apparent diffusion coefficient (ADC) values determination using magnetic resonance imaging (MRI) and diffusion-weighted MRI (DWI).

on T2-weighted images, identified on T2-weighted images by air-fluid levels, as demonstrated in Figures 2A (sagittal slice) and Figure 2B (axial slice). DWI images (Figures $3 \mathrm{~A}$ and $3 \mathrm{~B}$ ) and its correspondent coloured ADC maps (Figure 3C) evinces lesion area (in yellow). Mean ADC value, measured in the coloured ADC map (Figure 3C) was $1.99 \times 10^{-3} \mathrm{~mm}^{2} / \mathrm{s}$.

Table 1. Total sample apparent diffusion coefficient values data of inflammatory lesions obtained by investigators (main results pertaining to ADC) that included inflammatory lesions in the group of benign lesions

\begin{tabular}{|c|c|c|c|c|}
\hline Study & Year & MRI & $\begin{array}{c}\text { Inflammatory lesion } \\
\text { considered }\end{array}$ & $\begin{array}{l}\text { Inflammatory lesion } \\
\text { ADC value reported }\end{array}$ \\
\hline Taha et al. [20] & 2014 & $1.5 \mathrm{~T}$ & $\begin{array}{l}\text { Mucocele, inflammatory polyp, fungal } \\
\text { sinusitis }\end{array}$ & $1.6 \times 10^{-3} \mathrm{~mm}^{2} / \mathrm{s}$ \\
\hline El-Gerby and El-Anwar [21] & 2017 & $1.5 \mathrm{~T}$ & $\begin{array}{c}\text { Acute chronic sinusitis, sinonasal polyps, } \\
\text { fungal sinusitis, mucocele } \\
\text { and Wegner's granulomatosis }\end{array}$ & $\begin{array}{l}\text { Ranged from } 1.54 \times 10^{-3} \mathrm{~mm}^{2} / \mathrm{s} \\
\text { to } 2.72 \times 10^{-3} \mathrm{~mm}^{2} / \mathrm{s}\end{array}$ \\
\hline Kilickesmez et al. [22] & 2018 & $1.5 \mathrm{~T}$ & Mucosal thickening & $2.23 \times 10^{-3} \mathrm{~mm}^{2} / \mathrm{s}$ \\
\hline Xiao et al. [31] & 2018 & $3 \mathrm{~T}$ & Inflammatory polyp & $\begin{array}{l}\text { Reported only for the group of } \\
\text { benign lesions }\end{array}$ \\
\hline Das et al. [32] & 2017 & $1.5 \mathrm{~T}$ & Inflammatory polyp & $1.84 \times 10^{-3} \mathrm{~mm}^{2} / \mathrm{s}$ \\
\hline Jiang et al.[33] & 2017 & $3 \mathrm{~T}$ & Inflammatory polyp & $1.61 \times 10^{-3} \mathrm{~mm}^{2} / \mathrm{s}$ \\
\hline Wang et al. [34] & 2017 & $3 \mathrm{~T}$ & Inflammatory polyp & $\begin{array}{l}\text { Reported only for the group of } \\
\text { benign lesions }\end{array}$ \\
\hline Sasaki et al. [35] & 2011 & $1.5 \mathrm{~T}$ & $\begin{array}{l}\text { Rhinosinusitis, inflammatory polyps, } \\
\text { fungal infection }\end{array}$ & $1.5 \times 10^{-3} \mathrm{~mm}^{2} / \mathrm{s}$ \\
\hline Sasaki et al. [36] & 2011 & $1.5 \mathrm{~T}$ & $\begin{array}{l}\text { Rhinosinusitis, inflammatory polyps, } \\
\text { fungal infection }\end{array}$ & $1.48 \times 10^{-3} \mathrm{~mm}^{2} / \mathrm{s}$ \\
\hline Razek et al. [37] & 2009 & $1.5 \mathrm{~T}$ & Inflammatory polyps & $1.95 \times 10^{-3} \mathrm{~mm}^{2} / \mathrm{s}$ \\
\hline White and Zhang [38] & 2008 & $1.5 \mathrm{~T}$ & Sinonasal secretions & Ranged from 2.91 to $35.7 \times 10^{-4} \mathrm{~mm}^{2} / \mathrm{s}$ \\
\hline
\end{tabular}

MRI = magnetic resonance imaging; $\mathrm{ADC}=$ apparent diffusion coefficient. 

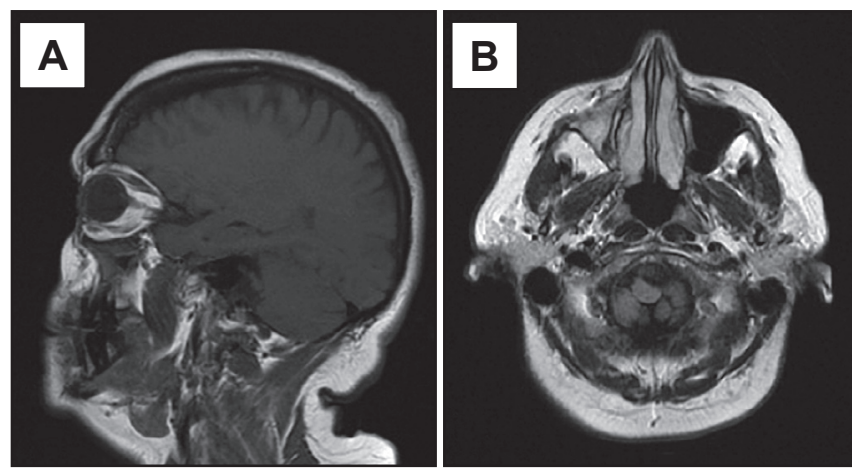

Figure 2. Air-fluid level: $A=T 2$-weighted sagittal slice shows the maxillary sinus cavity filled with homogeneous content; B = T2weighted axial slice.

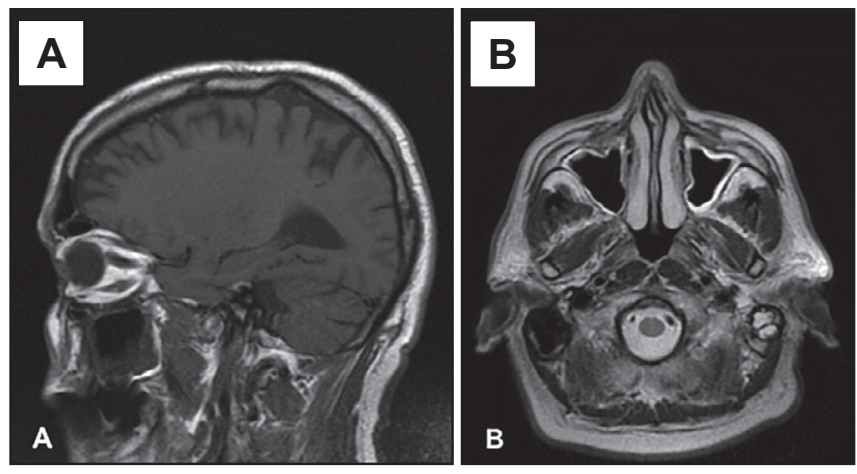

Figure 4. Mucosal thickening: $\mathrm{A}=$ sagittal slice; $\mathrm{B}=$ axial slice demonstrates hyperintense alteration surrounding all maxillary sinus internal walls.
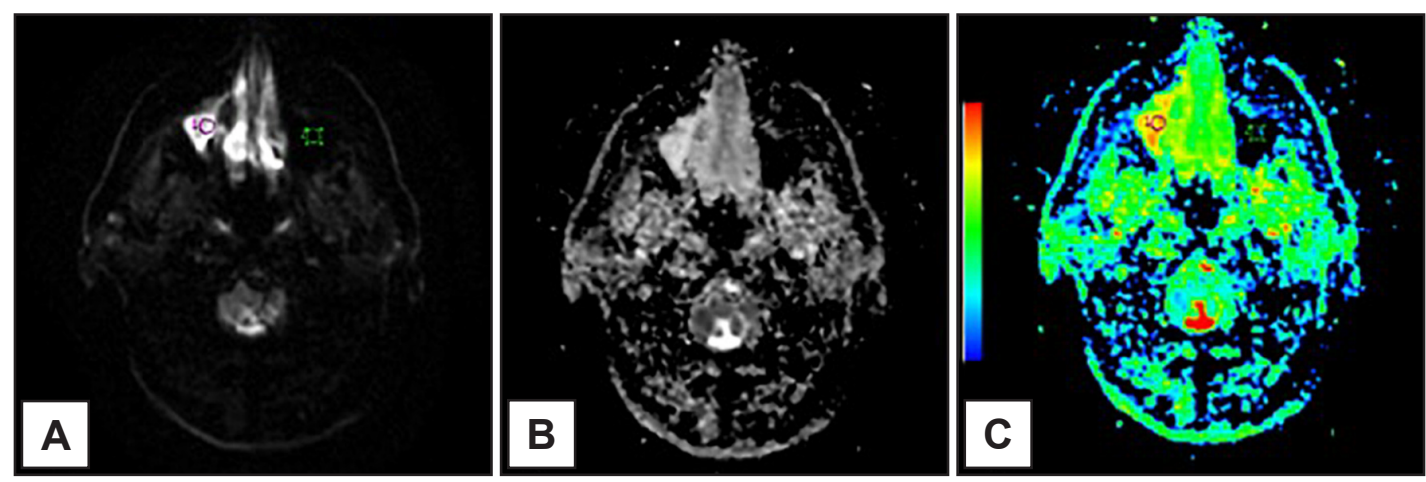

Figure 3. Air-fluid level: $A$ and $B=$ diffusion-weighted magnetic resonance imaging; $C=$ apparent diffusion coefficien (ADC) coloured map with lesion area (yellow colour).

Mean ADC value assessed was $1.99 \times 10^{-3} \mathrm{~mm}^{2} / \mathrm{s}$.

The presence of air-fluid levels may indicate acute rhinosinusitis, as well as be associated with any trauma to sinus cavity, such as in recent antral lavage, surgical procedures and mucociliary dysfunction secondary to intubation [17]. As the patient did not report any recent surgical procedure or intubation, nor recent antral lavage, the primary diagnosis hypothesis considered was acute rhinosinusitis.

\section{Case 2. Mucosal thickening}

A 70-year-old male patient was referred to MRI examination by his neurologist due to a previous stroke. Considering sinonasal complaints, patient mentioned no evident symptomatology, albeit former diagnosis of chronic rhinosinusitis from allergic origin was mentioned. In the case reported, mucosal thickening is exhibited with a hyperintense signal in T2-weighted image, surrounding all maxillary sinus internal walls, as described in Figure 4. In Figure 5, DWI and ADC map images; ADC mean value was $1.83 \times 10^{-3} \mathrm{~mm}^{2} / \mathrm{s}$.

Mucosal thickening may be present in a wide range of distinct cases, such as acute and chronic
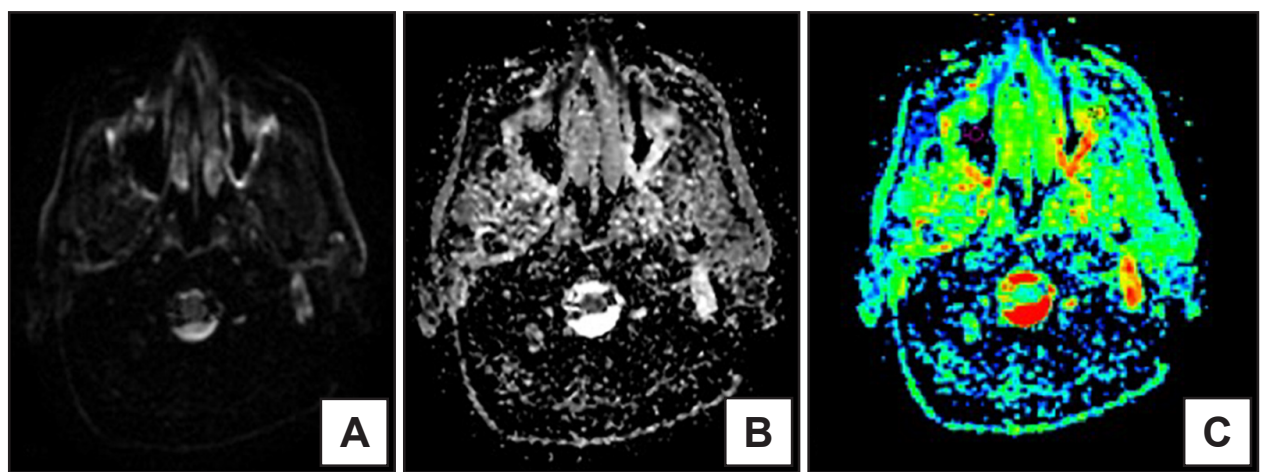

Figure 5. Mucosa thickening: $A$ and $B=$ diffusion-weighted magnetic resonance imaging; $C=$ apparent diffusion coefficien $(A D C)$ coloured map. Mean ADC value obtained from the ADC coloured map was $1.83 \times 10^{-3} \mathrm{~mm}^{2} / \mathrm{s}$. 
rhinosinusitis, from diverse pathogenic nature (fungi, virus, allergic) [17]. Although there is no consensus in literature $[\underline{7}, \underline{22}, \underline{23}]$, mucosal thickening up to 2 $\mathrm{mm}$ is considered normal [7]. However, mucosal thickening can also be present as an asymptomatic imaging finding [17], as exhibited in the current case reported.

\section{Case 3. Mucous retention cyst}

A 19-year-old male patient was referred to MRI examination by his neurologist due to chronic migraine complaint. Patient mentioned no sinonasal symptomatology. The mucous retention cyst was an MRI incidental imaging finding. In the present report, as demonstrated in Figure 6A, sagittal T2weighted slice shows an isointense rounded lesion, with a thin subtle surrounding well-demarcated limit, arising from the maxillary sinus floor and posterior wall. Axial T2-weighted slices (Figure 6B) exhibit a hyperintense lesion in left maxillary sinus. DWI image (Figure 7A and 7B) and its correspondent ADC map (Figure 7C) evinces lesion area. Mean ADC values, measured in the coloured ADC map (Figure $7 \mathrm{C})$ was $2.05 \times 10^{-3} \mathrm{~mm}^{2} / \mathrm{s}$.
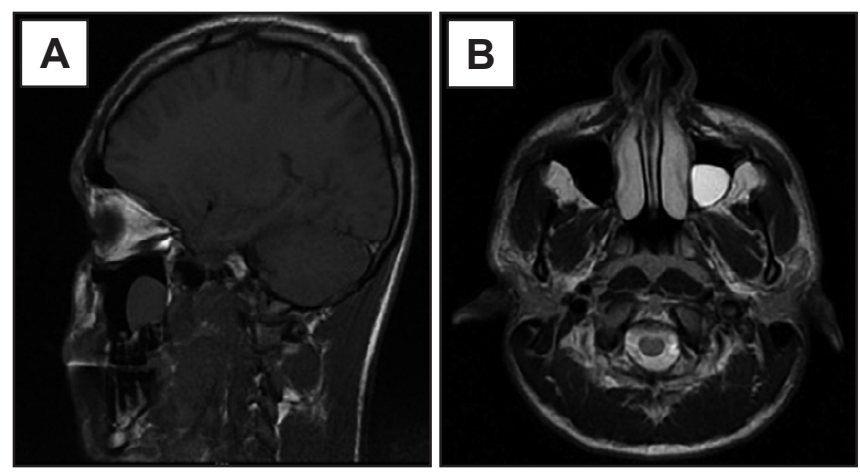

Figure 6. Mucous retention cyst: $\mathrm{A}=\mathrm{T} 2$-weighted sagittal slices exhibit a well-demarcated round-edge isointense lesion arising from the maxillary sinus floor and posterior wall; $\mathrm{B}=\mathrm{T} 2$-weighted axial slices exhibit a hyperintense round area.
Mucous retention cysts of the maxillary sinus are manifestations of chronic inflammatory sinus disease [24], and are usually asymptomatic [25], as presented in the case reported. On plain radiographs, they often exhibited a rounded-edge with a radiopaque internal content. Primary diagnosis was mucous retention cyst, although this lesion is similar to sinonasal polyps when considering particularly its imaging features [26].

\section{DISCUSSION}

Although computed tomography (CT) remains the preferable imaging examination for sinonasal study in dentistry, mainly due to its optimal resolution and ability to demonstrate bone tissue details, MRI has an essential complementary function in the diagnosis of inflammatory sinus disease, mainly due to its superior ability to characterize soft tissue pathologies [19].

Furthermore, MRI allows detecting inflammatory sinus disease spread, such as intracranial, perineural or orbital complications $[\underline{19}, 27]$. Regarding to sinonasal inflammatory pathology, MRI is appropriate to the study of acute or subacute sinusitis with associated orbital or intracranial complications with neurologic deficit; acute or subacute sinusitis in immunodeficient patients, sinonasal obstruction or suspected mass lesions [19]. Additionally, in cases of inflammatory diseases clinically detected with suspected symptoms, MRI should be the choice examination method, considering that MRI is an imaging examination which does not requires patient exposure to ionizing radiation [28]. However, the differentiation of sinonasal inflammatory lesions from neoplastic process is the main indication of MRI as a complementary tool to CT [27].

Gadolinium contrast media (GD) can be administered in MRI, essentially in the study of neoplastic processes [19], but towards inflammatory lesions, GD use is restricted. For inflammatory lesions,
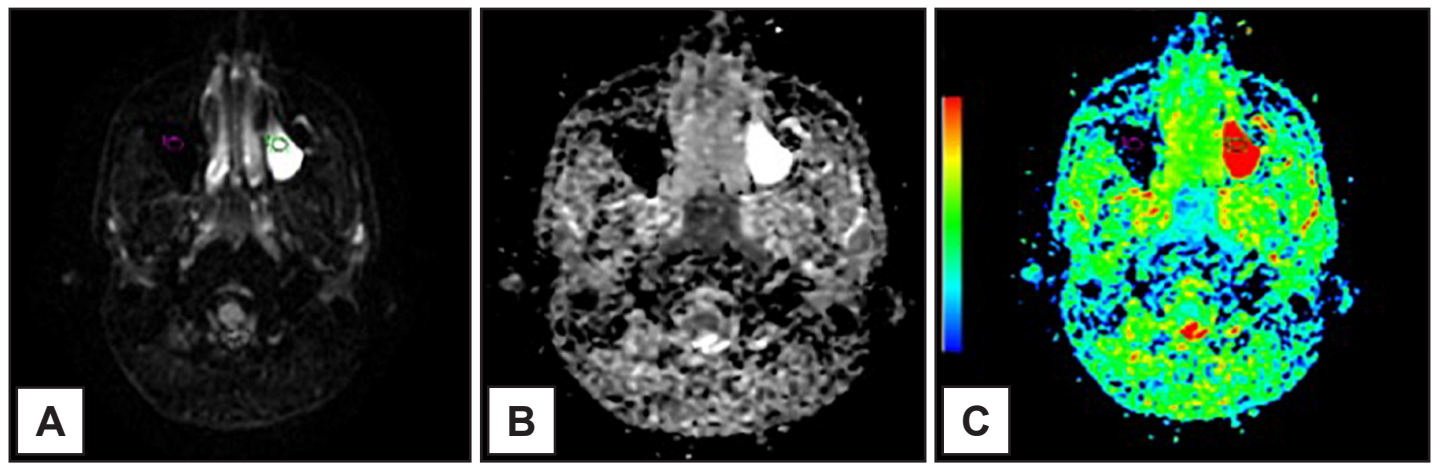

Figure 7. Mucous retention cyst: $\mathrm{A}$ and $\mathrm{B}=$ diffusion-weighted magnetic resonance imaging; $\mathrm{C}=$ apparent diffusion coefficien (ADC) coloured map.

Mean ADC value was $2.05 \times 10^{-3} \mathrm{~mm}^{2} / \mathrm{s}$ (red area). 
GD can be applied when an inflammatory lesion resembles malignancies, such as in the differentiation between malignant lesions from inflammatory polyps [29] or benign neoplasms from mucoceles [30].

DWI is an MRI complementary technique and its application in the investigation of distinct maxillofacial pathologies has been widely discussed in literature. The evaluation of random water molecule movements in intracellular medium provided by DWI and numerically described by $\mathrm{ADC}$ is useful to describe tissue cellularity and its physiological processes. The water molecule motion, named as "Brownian movements", can vary among distinct intercellular conditions and its restriction or diffusibility can be quantified by ADC and exhibited in ADC maps. The higher the water restriction, lower $\mathrm{ADC}$ values.

Studies considering DWI in paranasal sinus diseases available in literature focused essentially on ADC comparisons between groups of malignant neoplasms and benign lesions, considering a wide variety of inflammatory lesions in the group of benign lesions $[20,21,31-37]$. Inflammatory diseases exclusively were investigated by two studies $[22, \underline{38}]$ with distinct objectives and methodology.

White and Zhang [38] investigated the correlation between DWI features and sinonasal secretions in patients clinically diagnosed with inflammatory diseases. Sinonasal secretions may have a spectrum of MRI signal intensity, ranging from high to low both on T1 and T2-weighted images, and this variation is due to the effects of multiple secretions components, such as free water and mucus glycoproteins concentrations [39]. Considering the MRI signal variation and the aforementioned concept, researchers [38] observed a clear inverse correlation between ADC values and the protein concentration of the sinonasal secretions, which can provide useful information to the diagnosis of inflammatory disease. The ADC values ranged between 2.91 to $35.7 \times 10^{-3}$ $\mathrm{mm}^{2}$ and demonstrated a significant correlation with the signal intensity on T2-weighted images. Air fluid levels ADC values described in the present report was $1.99 \times 10^{-3} \mathrm{~mm}^{2} / \mathrm{s}$; lower than the range defined by the investigations.

Kilickesmez et al. [22] explored the relationship between mucosal thickening T1-weighted, T2weighted signals and ADC values with patient symptomatology, measured by three different quality life questionnaires. In this study, investigators described a mean ADC value of $2.23 \times 10^{-3} \mathrm{~mm}^{2} / \mathrm{s}$, which is higher than the present report mucosal thickening ADC mean value, which was $1.83 \times 10^{-3}$ $\mathrm{mm}^{2} / \mathrm{s}$. They concluded that $\mathrm{T} 1$ and $\mathrm{T} 2$-weighted signal intensities and mucosal thickening ADC values do not correlate with patient sinusal symptomatology. Among the studies that focused mainly in compare ADC in groups of malignant neoplasms and benign lesions, which included inflammatory lesions, some of them reported ADC values for inflammatory lesions. These are described in Table 1.

Notwithstanding, Sasaki et al. [35], when comparing malignant neoplasms and benign lesion ADC values, also noticed that ADC values differ significantly between fungal sinusitis and other inflammatory lesions. This finding was also confirmed by the same group of investigators, in a study published in the same year [36], when the concomitant use of timesignal intensity curve (TIC) and DWI were compared. Regarding to the cases reported, a lower ADC value was found in the presence of mucosal thickening when compared to retention cyst or air-fluid level. The lower ADC values of mucosal thickening found in this case may indicate higher water restriction in this alteration when compared to air-fluid level or mucous retention cyst. The explanation to the lower water diffusion in mucosal thickening may be in the cellular nature of this inflammatory process.

Mucosal thickening is a common imaging finding which can be associated with a number of sinus diseases, such as allergic, fungal, acute or chronic rhinosinusitis [17], as well as viral infections from the upper respiratory system [누] . As a response to pathogens, the sinus epithelial tissue becomes atypical [41] and exhibits extensive erosion [42] and inflammatory infiltrates [43], which indicates higher tissue cellularity when compared to the other alterations described in this report. Air-fluid levels and retention cysts are mainly composed of mucous secretions; which may facilitate water diffusibility.

Considering inflammatory polyps, Razek et al. [37] mentioned that the mean ADC was $1.9 \times 10^{3} \mathrm{~mm}^{2} / \mathrm{s}$, which is very similar to the ADC mean values assessed in the present case to mucosal retention cyst $\left(2.05 \times 10^{-3} \mathrm{~mm}^{2} / \mathrm{s}\right)$. Polyps imaging features may resemble mucous retention cysts imaging features [17], which may difficult their differentiation in MRI and probably leads to analogous mean ADC values obtained. Polyps, through mucosal hypertrophic protrusions, have manly oedematous contents [44] and its superficial cervices can accumulate mucous secretions [17]. The mucous secretion aggregation and the oedematous content may result in lower water restriction in this inflammatory alteration, similarly to mucous retention cysts.

Although ADC demonstrations from the presented cases and ADC from literature review were reported and compared, ADC values are influenced 
by a number of factors, such as patient-related factors, scanner stability, DWI acquisition parameters, equipment used, magnetic field intensity and systematic reader errors, which includes distinct ROI positioning or size strategies $[\underline{45}, \underline{46}]$. In the present report, the ROI positioning strategy was the use of $5 \mathrm{~cm}$ in the lesion center, considering its most significant part. However, distinct ROI positioning strategies were applied by the researchers mentioned in the review, such as flowing the margins of the solid part of the mass and avoiding cystic parts [37] or along the outer margin of the lesion [31] when differing malignant neoplasms from benign lesions. For studies including inflammatory lesions only, investigators placed the ROI on the secretion avoiding mucosal inflammation [38] or, in the case of mucosal thickening study, selecting the most restricted area observed in the ADC map.

\section{CONCLUSIONS}

In conclusion, it was observed that apparent diffusion coefficient values from the inflammatory lesions described in this report were different and apparent diffusion coefficient may be useful in the differentiation of these maxillary sinus alterations. Further larger sample investigations considering apparent diffusion coefficient values focusing in inflammatory lesions are recommended. The lack of studies considering the use of diffusionweighted magnetic resonance imaging on inflammatory diseases diagnostic was the major limitation of the literature review. Moreover, diffusion-weighted magnetic resonance imaging and apparent diffusion coefficient are complementary magnetic resonance imaging tools that may be easily applied in magnetic resonance imaging examinations, as a routine to sinonasal evaluations; the knowledge of lesions apparent diffusion coefficient reference values might be useful to differ distinct sinonasal lesions.

\section{ACKNOWLEDGMENTS AND DISCLOSURE STATEMENTS}

The authors report no conflicts of interest related to this study. The authors would like to thank $\mathrm{Dr}$ Ronaldo Abdala (Santa Casa de Misericórdia de Avaré, São Paulo, Brazil) for the technical support provided for this manuscript.

\section{REFERENCES}

1. Blanton PL, Biggs NL. Eighteen hundred years of controversy: the paranasal sinuses. Am J Anat. 1969;124(2):135-47. [Medline: 4886838] [doi: 10.1002/aja.1001240202]

2. Spaeth J, Krügelstein U, Schlöndorff G. The paranasal sinuses in CT-imaging: development from birth to age 25 . Int J Pediatr Otorhinolaryngol. 1997;39(1):25-40. [Medline: 9051437] [doi: 10.1016/S0165-5876(96)01458-9]

3. Hämmerle $\mathrm{CH}$, Araújo $\mathrm{MG}$, Simion $\mathrm{M}$; Osteology Consensus Group 2011. Evidence-based knowledge on the biology and treatment of extraction sockets. Clin Oral Implants Res. 2012;23 Suppl 5:80-2. [Medline: 22211307] [doi: 10.1111/j.1600-0501.2011.02370.x]

4. Ten Heggeler JM, Slot DE, Van der Weijden GA. Effect of socket preservation therapies following tooth extraction in non-molar regions in humans: a systematic review. Clin Oral Implants Res. 2011;22(8):779-88. [Medline: 21091540] [doi: 10.1111/j.1600-0501.2010.02064.x]

5. Biglioli F, Chiapasco M. An easy access to retrieve dental implants displaced into the maxillary sinus: the bony window technique. Clin Oral Implants Res. 2014;25(12):1344-51. [Medline: 24112544] [doi: 10.1111/clr.12276]

6. Tan WC, Lang NP, Zwahlen M, Pjetursson BE. A systematic review of the success of sinus floor elevation and survival of implants inserted in combination with sinus floor elevation. Part II: transalveolar technique. J Clin Periodontol. 2008; 35(8 Suppl):241-54. [Medline: 18724853] [doi: 10.1111/j.1600-051X.2008.01273.x]

7. Tadinada A, Fung K, Thacker S, Mahdian M, Jadhav A, Schincaglia GP. Radiographic evaluation of the maxillary sinus prior to dental implant therapy: A comparison between two-dimensional and three-dimensional radiographic imaging. Imaging Sci Dent. 2015;45(3):169-74. [Medline: 26389059] [doi: 10.5624/isd.2015.45.3.169]

8. Kayabasoglu G, Nacar A, Altundag A, Cayonu M, Muhtarogullari M, Cingi C. A retrospective analysis of the relationship between rhinosinusitis and sinus lift dental implantation. Head Face Med. 2014;10:53. [Medline: 25511309] [doi: 10.1186/1746-160X-10-53]

9. Manji A, Faucher J, Resnik RR, Suzuki JB. Prevalence of maxillary sinus pathology in patients considered for sinus augmentation procedures for dental implants. Implant Dent. 2013;22(4):428-35. [Medline: 23839271] [doi: 10.1097/ID.0b013e31829d1a20]

10. Kim YK, Hwang JY, Yun PY. Relationship between prognosis of dental implants and maxillary sinusitis associated with the sinus elevation procedure. Int J Oral Maxillofac Implants. 2013;28(1):178-83. [Medline: 23377064] [doi: 10.11607/jomi.2739] 
11. Wolf MK, Rostetter C, Stadlinger B, Locher M, Damerau G. Preoperative 3D imaging in maxillary sinus: brief review of the literature and case report. Quintessence Int. 2015;46(7):627-31. [Medline: 25918753] [doi: 10.3290/j.qi.a33930]

12. Nicolielo LF, Van Dessel J, Jacobs R, Martens W, Lambrichts I, Rubira-Bullen IR. Presurgical CBCT assessment of maxillary neurovascularization in relation to maxillary sinus augmentation procedures and posterior implant placement. Surg Radiol Anat. 2014;36(9):915-24. [Medline: 24828124] [doi: 10.1007/s00276-014-1309-3]

13. Yatani H, Komiyama O, Matsuka Y, Wajima K, Muraoka W, Ikawa M, Sakamoto E, De Laat A, Heir GM. Systematic review and recommendations for nonodontogenic toothache. J Oral Rehabil. 2014 Nov;41(11):843-52. [Medline: 25040436] [doi: 10.1111/joor.12208]

14. Joshi VM, Sansi R. Imaging in Sinonasal Inflammatory Disease. Neuroimaging Clin N Am. 2015;25(4):549-68. [Medline: 26476379] [doi: 10.1016/j.nic.2015.07.003]

15. Maillet M, Bowles WR, McClanahan SL, John MT, Ahmad M. Cone-beam computed tomography evaluation of maxillary sinusitis. J Endod. 2011;37(6):753-7. [Medline: 21787483] [doi: 10.1016/j.joen.2011.02.032]

16. Tyndall DA, Price JB, Tetradis S, Ganz SD, Hildebolt C, Scarfe WC; American Academy of Oral and Maxillofacial Radiology. Position statement of the American Academy of Oral and Maxillofacial Radiology on selection criteria for the use of radiology in dental implantology with emphasis on cone beam computed tomography. Oral Surg Oral Med Oral Pathol Oral Radiol. 2012 Jun;113(6):817-26. [Medline: 22668710] [doi: 10.1016/j.0000.2012.03.005]

17. Mossa-Basha M, Blitz AM. Imaging of the paranasal sinuses. Semin Roentgenol. 2013;48(1):14-34. [Medline: 23158048] [doi: 10.1053/j.ro.2012.09.006]

18. Hähnel S, Ertl-Wagner B, Tasman AJ, Forsting M, Jansen O. Relative value of MR imaging as compared with CT in the diagnosis of inflammatory paranasal sinus disease. Radiology. 1999;210(1):171-6. [Medline: 9885603] [doi: 10.1148/ radiology.210.1.r99ja36171]

19. Huang BY, Senior BA, Castillo M. Current Trends in Sinonasal Imaging. Neuroimaging Clin N Am. 2015;25(4):507-25. [Medline: 26476377] [doi: 10.1016/j.nic.2015.07.001]

20. Taha MS, El Fiky LM, Taha TM, Sabra RM, Youssef TA, Nada IM. Utility of apparent diffusion coefficient in characterization of different sinonasal pathologies. Am J Rhinol Allergy. 2014;28(5):181-6. [Medline: 25198015] [doi: 10.2500/ajra.2014.28.4098]

21. El-Gerby KM, El-Anwar MW. Differentiating Benign from Malignant Sinonasal Lesions: Feasibility of Diffusion Weighted MRI. Int Arch Otorhinolaryngol. 2017;21(4):358-65. [Medline: 29018499] [doi: 10.1055/s-0036-1597323]

22. Kilickesmez O, Onerci Celebi O, Yalcinkaya M, Gokduman AR, Karagoz Y, Yigit O. Correlation of quantitative MR imaging findings with symptoms in patients with incidentally detected inflammatory sinonasal disease. Diagn Interv Imaging. 2018. 99(2):65-72. [Medline: 28729182] [doi: 10.1016/j.diii.2017.05.012]

23. Lu Y, Liu Z, Zhang L, Zhou X, Zheng Q, Duan X, Zheng G, Wang H, Huang D. Associations between maxillary sinus mucosal thickening and apical periodontitis using cone-beam computed tomography scanning: a retrospective study. J Endod. 2012 Aug;38(8):1069-74. [Medline: 22794207] [doi: 10.1016/j.joen.2012.04.027]

24. Harar RP, Chadha NK, Rogers G. Are maxillary mucosal cysts a manifestation of inflammatory sinus disease? J Laryngol Otol. 2007;121(8):751-4. [Medline: 17250779] [doi: 10.1017/S0022215107005634]

25. Donizeth-Rodrigues C, Fonseca-Da Silveira M, Gonçalves-De Alencar AH, Garcia-Santos-Silva MA, FranciscoDe-Mendonça E, Estrela C. Three-dimensional images contribute to the diagnosis of mucous retention cyst in maxillary sinus. Med Oral Patol Oral Cir Bucal. 2013;18(1):e151-7. [Medline: 23229251] [doi: 10.4317/medoral.18141]

26. Mafee MF, Tran BH, Chapa AR. Imaging of rhinosinusitis and its complications: plain film, CT, and MRI. Clin Rev Allergy Immunol. 2006;30(3):165-86. [Medline: 16785588] [doi: 10.1385/CRIAI:30:3:165]

27. Betts AM, Cornelius R. Magnetic resonance imaging in sinonasal disease. Top Magn Reson Imaging. 2015;24(1):15-22. [Medline: 25654418] [doi: 10.1097/RMR.0000000000000043]

28. Giotakis EI, Weber RK. Cysts of the maxillary sinus: a literature review. Int Forum Allergy Rhinol. 2013;3(9):766-71. [Medline: 23677671] [doi: 10.1002/alr.21177]

29. Sievers KW, Greess H, Baum U, Dobritz M, Lenz M. Paranasal sinuses and nasopharynx CT and MRI. Eur J Radiol. 2000;33(3):185-202. [Medline: 10699736] [doi: 10.1016/S0720-048X(99)00142-4]

30. Lanzieri CF, Shah M, Krauss D, Lavertu P. Use of gadolinium-enhanced MR imaging for differentiating mucoceles from neoplasms in the paranasal sinuses. Radiology. 1991;178(2):425-8. [Medline: 1987603] [doi: 10.1148/radiology.178.2.1987603]

31. Xiao Z, Tang Z, Qiang J, Wang S, Qian W, Zhong Y, Wang R, Wang J, Wu L, Tang W, Zhang Z. Intravoxel Incoherent Motion MR Imaging in the Differentiation of Benign and Malignant Sinonasal Lesions: Comparison with Conventional Diffusion-Weighted MR Imaging. AJNR Am J Neuroradiol. 2018 Jan 25. [Medline: 29371251] [doi: 10.3174/ajnr.A5532]

32. Das A, Bhalla AS, Sharma R, Kumar A, Thakar A, Vishnubhatla SM, Sharma MC, Sharma SC. Can Diffusion Weighted Imaging Aid in Differentiating Benign from Malignant Sinonasal Masses?: A Useful Adjunct. Pol J Radiol. 2017 Jun 28;82:345-355. [Medline: 28740564] [doi: 10.12659/PJR.900633]

33. Jiang Jx, Tang ZH, Zhong YF, Qiang JW. Diffusion kurtosis imaging for differentiating between the benign and malignant sinonasal lesions. J Magn Reson Imaging. 2017;45(5):1446-54. [Medline: 27758016] [doi: 10.1002/jmri.25500] 
34. Wang F, Sha Y, Zhao M, Wan H, Zhang F, Cheng Y, Tang W. High-Resolution Diffusion-Weighted Imaging Improves the Diagnostic Accuracy of Dynamic Contrast-Enhanced Sinonasal Magnetic Resonance Imaging. J Comput Assist Tomogr. 2017 Mar/Apr;41(2):199-205. [Medline: 27560026] [doi: 10.1097/RCT.0000000000000502]

35. Sasaki M, Eida S, Sumi M, Nakamura T. Apparent diffusion coefficient mapping for sinonasal diseases: differentiation of benign and malignant lesions. AJNR Am J Neuroradiol. 2011;32(6):1100-6. [Medline: 21393402] [doi: 10.3174/ajnr.A2434]

36. Sasaki M, Sumi M, Eida S, Ichikawa Y, Sumi T, Yamada T, Nakamura T. Multiparametric MR imaging of sinonasal diseases: time-signal intensity curve- and apparent diffusion coefficient-based differentiation between benign and malignant lesions. AJNR Am J Neuroradiol. 2011 Dec;32(11):2154-9. [Medline: 21920869] [doi: 10.3174/ajnr.A2675]

37. Razek AA, Sieza S, Maha B. Assessment of nasal and paranasal sinus masses by diffusion-weighted MR imaging. J Neuroradiol. 2009;36(4):206-11. [Medline: 19577300] [doi: 10.1016/j.neurad.2009.06.001]

38. White ML, Zhang Y. Sinonasal secretions: evaluation by diffusion-weighted imaging and apparent diffusion coefficients. Clin Imaging. 2008;32(5):382-6. [Medline: 18760726] [doi: 10.1016/j.clinimag.2007.12.007]

39. Dillon WP, Som PM, Fullerton GD. Hypointense MR signal in chronically inspissated sinonasal secretions. Radiology. 1990;174(1):73-8. [Medline: 2294574] [doi: 10.1148/radiology.174.1.2294574]

40. Desrosiers M, Evans GA, Keith PK, Wright ED, Kaplan A, Bouchard J, Ciavarella A, Doyle PW, Javer AR, Leith ES, Mukherji A, Robert Schellenberg R, Small P, Witterick IJ. Canadian clinical practice guidelines for acute and chronic rhinosinusitis. J Otolaryngol Head Neck Surg. 2011 May;40 Suppl 2:S99-193. [Medline: 21658337] [doi: $10.1186 / 1710-1492-7-2]$

41. Dorgam JV, Souza BB, Sarreta SMC, Melo VR, Anselmo-Lima WT. Histology and ultrastructural study of the mucosa of the maxillary sinus in patients with chronic rhinosinusitis and nasosinusal polyposis. Rev Bras Otorrinolaringol. 2004 Jan-Feb;70(1):7-13. [doi: 10.1590/S0034-72992004000100002]

42. Stanciu G, Mogoantă CA, Ioniţă E, Timnea OC, Mateescu GO, Ionovici N, Pop OT, Gheorghişor I. Histopathological and immunohistochemical aspects in chronic suppurative maxillary rhinosinusitis. Rom J Morphol Embryol. 2011;52(4): 1337-41. [Medline: 22203943]

43. Nonoyama T, Harada T, Shinogi J, Yoshimura E, Sakakura Y. Immunohistochemical localization of cytokines and cell adhesion molecules in maxillary sinus mucosa in chronic sinusitis. Auris Nasus Larynx. 2000;27(1):51-8. [Medline: 10648069] [doi: 10.1016/S0385-8146(99)00042-5]

44. Mortuaire G, Leroyx, Gengler I, Chevalier D, Prin L, Picry A. Histopathological classification of refractory chronic rhinosinusitis with nasal polyps. Histol Histopathol. 2015;30(12):1447-54. [Medline: 25986951]

45. Giannotti E, Waugh S, Priba L, Davis Z, Crowe E, Vinnicombe S. Assessment and quantification of sources of variability in breast apparent diffusion coefficient (ADC) measurements at diffusion weighted imaging. Eur J Radiol. 2015;84(9): 1729-36. [Medline: 26078100] [doi: 10.1016/j.ejrad.2015.05.032]

46. Wenkel E, Geppert C, Schulz-Wendtland R, Uder M, Kiefer B, Bautz W, Janka R. Diffusion weighted imaging in breast MRI: comparison of two different pulse sequences. Acad Radiol. 2007 Sep;14(9):1077-83. [Medline: 17707315] [doi: 10.1016/j.acra.2007.06.006]

\section{To cite this article:}

Munhoz L, Abdala Júnior R, Abdala R, Asaumi J, Arita ES.

Diffusion-Weighted Magnetic Resonance Imaging in Maxillary Sinuses Inflammatory Diseases: Report of Three Cases and Literature Review

J Oral Maxillofac Res 2018;9(2):e4

URL: http://www.ejomr.org/JOMR/archives/2018/2/e4/v9n2e4.pdf

doi: $10.5037 /$ jomr.2018.9204

Copyright (C) Munhoz L, Abdala Júnior R, Abdala R, Asaumi J, Arita ES. Published in the JOURNAL OF ORAL \& MAXILLOFACIAL RESEARCH (http://www.ejomr.org), 29 June 2018.

This is an open-access article, first published in the JOURNAL OF ORAL \& MAXILLOFACIAL RESEARCH, distributed under the terms of the Creative Commons Attribution-Noncommercial-No Derivative Works 3.0 Unported License, which permits unrestricted non-commercial use, distribution, and reproduction in any medium, provided the original work and is properly cited. The copyright, license information and link to the original publication on (http://www.ejomr.org) must be included. 